\title{
Multi-purpose Bonding Performance of Newly Synthesized Phosphonic Acid Monomers
}

\author{
Kunio IKEMURA ${ }^{1}$, Franklin R. TAY ${ }^{2}$, Norihiro NISHIYAMA ${ }^{3}$, David H. PASHLEY ${ }^{2}$ and Takeshi ENDO ${ }^{4,5}$ \\ ${ }^{1}$ Department of Research and Development, Shofu Inc., 11 kamitakamatsu-cho, Fukuine, Higashiyama-ku, Kyoto 605-0983, \\ Japan \\ ${ }^{2}$ Department of Oral Biology and Maxillofacial Pathology, School of Dentistry, Medical College of Georgia, Augusta, \\ Georgia, USA \\ ${ }^{3}$ Department of Dental Materials, Research Institute of Oral Science, Nihon university School of Dentistry at Matsudo, 2- \\ 870-1 Sakaecho Nishi, Matsudo, Chiba 271-8587, Japan \\ ${ }^{4}$ Molecular Engineering Institute, Kinki University, 11-6 Kayanomori, Iizuka, Fukuoka 820-8555, Japan \\ ${ }^{5}$ Research Laboratory of Resources Utilization, Tokyo Institute of Technology, 4259 Nagatsuta-cho, Midori-ku, Yokohama \\ 226-8503, Japan \\ Corresponding author, Kunio IKEMURA; E-mail: k-ikemura@shofu.co.jp
}

Received July 20, 2006/Accepted October 19, 2006

\begin{abstract}
Multi-purpose bonding performance of three kinds of newly synthesized phosphonic acid monomers was investigated. Methacryloxyalkyl or acryloxyalkyl phosphonoacetates of 6-MHPA, 6-AHPA, 10-MDPA were synthesized in 42.8-51.9\% yields with a light yellow viscous liquid, and identified as new compounds by ${ }^{1} \mathrm{H}$ NMR, IR, and elemental analysis. Conventional adhesive monomers, namely VBPA, 4-META, and 4-AETA, and CEBA-p-TSMo- $t$-BPMA initiator were also used. Seven experimental composite-type adhesive resins comprising these six kinds of adhesive monomers and None (control) with the initiator were prepared. Tensile bond strengths of adhesive resins to unetched ground enamel and dentin, ground porcelain, and sandblasted Ni-Cr alloy were measured at a crosshead speed of $1.0 \mathrm{~mm} / \mathrm{min}$. Results showed that except with VBPA, there were no significant differences among 6-MHPA, 6-AHPA, 10-MDPA, 4-AETA, and 4-META in bonding performance to the adherends $(\mathrm{p}<0.01)$. It was found that the new phosphonic acid monomers provided good multipurpose adhesion to all adherends tested.
\end{abstract}

Keywords: Phosphonic acid monomers, Polymerization initiator, Multi-purpose bonding performance

\section{INTRODUCTION}

To develop a super-adhesive monomer that should perform stronger adhesion to hard dental tissues, numerous challenges of chemical-approach study on molecular design have been continuously performed by means of synthetic organic chemistry ${ }^{1-22)}$. Adhesive monomers can be defined as radical polymerizable monomers bearing both hydrophilic and hydrophobic moieties in the structure ${ }^{11}$. Their bonding performance can be mainly influenced by their hydrophilic acidic moieties that include the carboxylic acid $(-\mathrm{COOH})$ or its anhydride group, and the phosphoric acid group [-O-P $\left.(=\mathrm{O})(\mathrm{OH})_{2}\right]$. Phosphate monomers bearing phosphoric acid group have been well investigated $^{2-5)}$, whereby 2-methacryloyloxyethylphenyl hydrogen phosphate (Phenyl-P) ${ }^{2-3)}$ and 10-methacryloyloxydecyl dihydrogen phosphate (10-MDP $)^{4}$ have been commercially utilized. Contrary to these phosphate monomers, regarding phosphonic acid $\left[-\mathrm{P}(=\mathrm{O})(\mathrm{OH})_{2}\right]$ monomers, 4-vinylbenzylphosphonic acid (VBPA) and vinylphosphonic acid (VPA) were initially proposed for bonding to the hard dental tissues ${ }^{6}$. However, they formulated with ethyl alcohol, and did not show significant efficacy on bonding to the teeth ${ }^{6}$. Despite the lack of early success, recently synthesized phosphonic acid monomers appeared to be hydrolytically stable in self-etching primers or adhesives $^{7-13)}$ and hence seemed promising. However, since these investigations ${ }^{7.13)}$ have not been extended beyond water-based adhesives, little is known about the multi-purpose bonding performance of phosphonic acid monomers with polymerization initiators in hydrophobic adhesive resins.

To improve bond strength via the molecular structure of adhesive monomers, the design should exploit the flexible methylene chain as well as acidic hydrophilic groups in the structure ${ }^{4,14}$. In a recent work $^{15)}$, phosphonic acid monomers of methacryloxyalkyl or acryloxyalkyl 3-phosphonopropionates, in particular those with long alkyl spacers, provided strong adhesion to unetched ground enamel and sandblasted $\mathrm{Ni}-\mathrm{Cr}$ alloy when they were formulated into self-cured adhesive resins using a ternary polymerization initiator, benzoyl peroxide (BPO)- $N, N$-di (hydroxyethyl)-p-toluidine (DEPT) -1-benzyl-5-phenyl barbituric acid (BPBA). Both C6 (carbon number equal to 6) and $\mathrm{C} 10$, as flexible methylene chains, contributed significantly to enhancing the bonding efficacy as well as the phosphonic acid moiety ${ }^{15}$.

While acidic adhesive monomers have a potential of good chemical interaction with tooth substrates, the acidic group (electron acceptor) reacts with an aromatic tertiary amine (electron donor) of 
polymerization initiator system to form yellowish salts ${ }^{16,23)}$. To circumvent the degraded adhesion and delayed polymerization caused by the formation of yellowish salts ${ }^{16,23)}$ or undesirable quaternary ammonium salts ${ }^{24)}$ of acidic adhesive monomers with a conventional redox initiator of BPO-DEPT, ternary initiator systems, such as BPO-DEPT-BPBA and 1cyclohexyl -5- ethylbarbituricacid (CEBA) - $p$ - toluenesufinate morphoride ( $p$-TSMo) -tert- butylperoxymaleic acid ( $t$-BPMA) were previously developed ${ }^{23)}$.

To develop a multi-purpose adhesive resin, the aims of this study were: (1) to synthesize three kinds of newly designed phosphonic acid monomers of 6methacryloxyhexyl phosphonoacetate (6-MHPA), 6acryloxyhexyl phosphonoacetate (6-AHPA), and 10methacryloxydecyl phosphonoacetate (10-MDPA); (2) to evaluate their multi-purpose bonding performance to unetched ground enamel and dentin, ground dental porcelain, and sandblasted dental metal, together with a polymerization initiator CEBA-p-TSMo- $t$ $\mathrm{BPMA}^{23}$; and (3) to compare the bonding of 6-MHPA, 6-AHPA, and 10-MDPA against that of 4methacryloxyethyltrimellitic anhydride (4-META), 4acryloxyethyltrimellitic anhydride (4-AETA), and conventional VBPA.

As comparison of bonding performance was based on molecular structure, VBPA was selected as a control with no flexible alkyl moiety in the structure, while methacrylic and acrylic esters were selected because of the bearing of trimellitic anhydride moiety (4-META and 4-AETA). For this study, the null hypothesis was that there were no significant differences between the new (6-MHPA, 6-AHPA, 10MDPA) and conventional (VBPA) phosphonic acid monomers with CEBA-p-TSMo-t-BPMA initiator on adhesion.

\section{MATERIALS AND METHODS}

Synthesis of new phosphonic acid monomers

Figure 1 shows a schematic illustration of the synthesis of seven kinds of phosphonic acid monomers $\left[\mathrm{R}-\mathrm{P}(=\mathrm{O})(\mathrm{OH})_{2}\right](3$, Fig. 1C) in our research series - in this work (3, $\mathrm{m}=1$, Fig. $1 \mathrm{C})$ and in a previous work $(3, \mathrm{~m}=2 \text {, Fig. } 1 \mathrm{C})^{15)}$, as well as the synthesis of adhesive monomers bearing carboxylic acid or its anhydride ${ }^{14,19,21,23)}$. The phosphonic acid monomers were synthesized by esterification of monohydroxyalkyl methacrylates or acrylates (2, Fig. 1C) with 2-carboxyalkyl phosphonic acid (1, Fig. 1A), according to a previously disclosed patent ${ }^{21)}$.

1) 6-Methacryloxyhexyl phosphonoacetate (6-MHPA) To a stirred mixture of 1,6-hexamethylene glycol (236.3 g, $2.0 \mathrm{~mol}$ ), pyridine (118 g, $1.5 \mathrm{~mol}$ ), and tetrahydrofuran $(1.2 \mathrm{~L})$, methacrylic chloride (209 g, 2.0 mol) was added drop-wise for 2-3 hours at 10-15 ${ }^{\circ} \mathrm{C}$, and further reacted at $15^{\circ} \mathrm{C}$ for four hours. After removing precipitated pyridine hydrochloric salts (Py$\mathrm{HCl}$ ) and solvent, reaction mixture was purified by separation through column chromatography and pure 6-hydroxyhexyl methacrylate (6-HHMA) $\left(2, \mathrm{R}=\mathrm{CH}_{3}\right.$, $\mathrm{n}=6$, Fig. 1C) $(70 \mathrm{~g})$ was obtained. The mixture of triethylphosphite $(664.6 \mathrm{~g}, 4.0 \mathrm{~mol})$ and ethyl bromoacetate $(334.0 \mathrm{~g}, 2.0 \mathrm{~mol})$ was refluxed for four hours. After distillation of the reaction mixture, ethyl diethylphosphonoacetate (EPA) [1', m=1, Fig. 1A(b)] was obtained. Following which, the EPA was hydrolyzed with $38 \%$ hydrobromic acid aqueous solution and purified by recrystalization from acetone with ethyl acetate, thereby obtaining phosphonoacetic acid (PPA) (white crystals, $\mathrm{mp} 144-146^{\circ} \mathrm{C}$ ) (160 g) $[1, \mathrm{~m}=1$, Fig. 1A(a)]. 6-HHMA (65 g, $0.35 \mathrm{~mol})$ was then reacted with PAA $(35 \mathrm{~g}, 0.25 \mathrm{~mol})$ at $80-100^{\circ} \mathrm{C}$ under 200-300 mmHg for six hours. The reaction product was purified, and a light yellow viscous product (40 g) was obtained.

2) 6-Acryloxyhexyl phosphonoacetate (6-AHPA)

6-Hydroxyhexylacrylate (6-HHAA) $(2, \mathrm{R}=\mathrm{H}, \mathrm{n}=6$, Fig. 1C) was synthesized by esterification between acrylic chloride and 1,6-hexamethylene glycol in a manner similar to the synthesis of 6-HHMA. The title compound was synthesized by esterification of 6-HHAA (60.2 g, $0.35 \mathrm{~mol})$ with PPA (35 g, $0.25 \mathrm{~mol})$ for six hours at $70-100^{\circ} \mathrm{C}$ under $200-300 \mathrm{mmHg}$ in a manner similar to the synthesis of 6-MHPA, and a light yellow oily product $(30 \mathrm{~g})$ was obtained.

3) 10-Methacryloxydecyl phosphonoacetate (10-MDPA) Esterification of 1,10-decamethylene glycol (349 g, 2.0 mol) and methacrylic acid (103 g, $1.2 \mathrm{~mol}$ ) was carried out for six hours at $90^{\circ} \mathrm{C}$ under $80-100 \mathrm{mmHg}$. The reaction mixture was separated through column chromatography, and pure 10-hydroxydecylmethacrylate (10-HDMA) $\left(2, \mathrm{R}=\mathrm{CH}_{3}, \mathrm{n}=10\right.$, Fig. 1$)(100 \mathrm{~g}$, $0.41 \mathrm{~mol}$ ) was obtained. 10-HDMA (73 g, $0.30 \mathrm{~mol}$ ) was then reacted with PPA $(35 \mathrm{~g}, 0.25 \mathrm{~mol})$ in toluene $(80 \mathrm{~g})$ at $70-110^{\circ} \mathrm{C}$ for 6.5 hours under $200-300$ $\mathrm{mmHg}$ vacuum in a manner similar to the synthesis of 6-MHPA. The purified product obtained was a light yellow viscous liquid (40 g).

Identification of synthesized (meth) acryloxyalkyl phosphonoacetates

Structures of the synthesized products were identified by proton nuclear magnetic resonance spectroscopy $\left({ }^{1} \mathrm{H}\right.$ NMR). The NMR spectra were taken with a JNM-AL300 (300 MHZ) spectrometer (JEOL, Tokyo, Japan) with tetramethylsilane (TMS) as an internal standard. Infra-red (IR) spectra measurements were performed on a Fourier transform-infra red (FT-IR) spectrometer (FT-300, Horiba Co. Ltd., Kyoto, Japan). Elemental analysis was conducted using an Elemental Organic Analyzer (CHN CORDER, Model MT-3, Yanaco Analytical Instruments Co., Kyoto, Japan). 


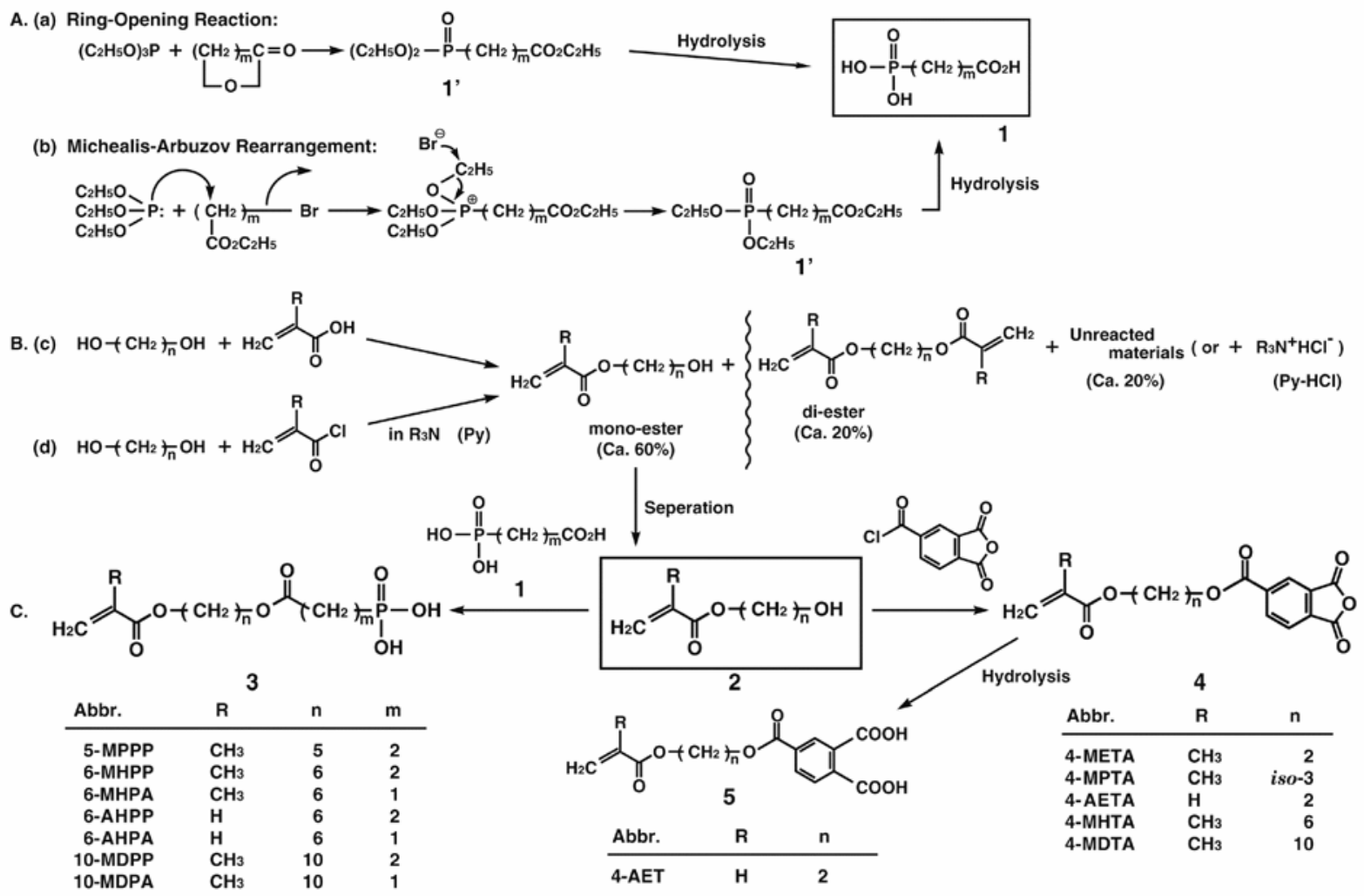

Fig. 1 General schema of the syntheses of seven kinds of novel phosphonic acid monomers (3) in our research series, i. e., 6-methacryloxyhexyl phosphonoacetate (6-MHPA), 6-acryloxyhexyl phosphonoacetate (6-AHPA), and 10methacryloxydecyl phosphonoacetate (10-MDPA) in this work, as well as 5-methacryloxypentyl 3phosphonopropionate (5-MPPP), 6-methacryloxyhexyl 3-phosphonopropionate (6-MHPP), 6-acryloxyhexyl 3phosphonopropionate (6-AHPP), and 10-methacryloxydecyl 3-phosphonopropionate (10-MDPP) in a previous work $^{15)}$, together with the schema of syntheses of 4-acryloxyethyltrimellitic acid (5: 4-AET) ${ }^{14,19,23)}$, 4acryloxyethyltrimellitic anhydride (4: 4-AETA $)^{14,19,23)}$, 4-methacryloxyethyltrimellitic anhydride (4: 4-META $)^{1,14)}$, 4methacryloyloxy-iso-propyltrimellitic anhydride (4: 4-MPTA $)^{14)}$, 4-methacryloyloxyhexyl trimellitic anhydride (4: 4-MHTA $)^{14)}$ and 4-methacryloyloxydecyl trimellitic anhydride (4: 4-MDTA $)^{14}$. A: For the formation of carbon-phosphorus bonds $[>\mathrm{P}(=\mathrm{O})-\mathrm{C}]$, the alkyl-dialkylphosphonate [1': R1OOC-R2-P(=O)(OR1)2] can be synthesized by either (a) the ring-opening reaction of alkyl lactone compounds with trialkylphosphite or (b) the Michaelis-Arbuzov rearrangement, which is the reaction of trialkylphosphite with alkyl-alkylcarboxylate hal$\operatorname{ides}^{30)}$. During the transformation, a tervalent phosphorus $[\mathrm{P}(\mathrm{III})]$ is converted into a pentavalent phosphorus $[\mathrm{P}(\mathrm{V})]$, which involves the conversion of $>\mathrm{P}-\mathrm{O}-\mathrm{C}$ linkage into $>\mathrm{P}(=\mathrm{O})-\mathrm{C}$ linkage ${ }^{30}$. B: Since the esterification of (c) or (d) formed reaction mixture containing monoester, diester, and unreacted materials, the main mono $\mathrm{OH}$ monomer should be separated chromatographically to obtain the pure monohydroxyalkyl methacrylate or acrylate (2). C: Seven kinds of (3) phosphonic acid monomers were synthesized by the esterification between the $\mathrm{OH}$ monomer 2 and carboxyalkyl phosphonic acids (1). The $\mathrm{OH}$ monomer 2 previously reacted with anhydrous trimellitic chloride to yield the corresponding adhesive monomers (4 and 5) of 4-AETA ${ }^{14,19,23)}$, 4-AET ${ }^{14,19,21,23)}$, 4-META ${ }^{1,14)}$, 4-MPTA ${ }^{14)}$, 4-MHTA ${ }^{14)}$, and 4-MDTA ${ }^{14)}$. Adhesive monomers of 6-MHPA, 6-AHPA, 10-MDPA, 4-AETA, and 4-META were used in this study.

Preparation of a CEBA-p-TSMo-t-BPMA polymerization initiator system

The component of $\boldsymbol{p}$-TSMo (light yellow crystals, $\mathrm{mp}$ $120-123^{\circ} \mathrm{C}$ ) was synthesized by the reaction of morphorine with $p$-toluenesulfinic chloride ( $p$-TSCl), where the latter was synthesized by the reaction of $p$-toluenesulfic acid sodium salt dihydrate ( $p$-TSNa) with thionyl chloride, according to a method previously reported ${ }^{23)}$. As for CEBA (white needle crystals, mp $115-117.5^{\circ} \mathrm{C}$ ), it was synthesized according to a method previously reported ${ }^{23,25)}$. As for $\underline{t}$ BPMA, it was purchased from Nihon Oil and Fat Co. Ltd. (Tokyo, Japan) and used without further purification. Figure 2 is a schematic illustration of the synthesis of $p$-TSMo and the structures of polymerization initiators, CEBA and $t$-BPMA. 
p-TSMo:

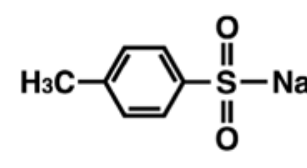<smiles>O=S1(=O)CCCSC1</smiles><smiles>Cc1ccc(S(C)(=O)=O)cc1N=NOS(=O)(=O)Cl</smiles>

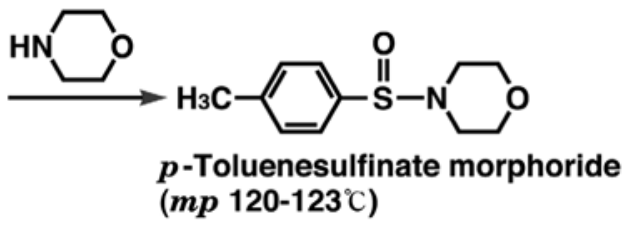

CEBA:

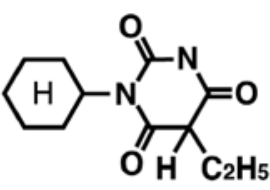

\section{1-Cyclohexyl-5-ethylburbituric acid} $\left(\operatorname{mp} 115.0-117.5^{\circ} \mathrm{C}\right)$

$\boldsymbol{t}$-BPMA:<smiles>CC(C)(C)COOC(=O)C=CC(=O)O</smiles>

\section{tert -Butylperoxymaleic acid}

Fig. 2 Schematic illustration of the structures of ternary polymerization initiator, CEBA- $p$-TSMo- $t$-BPMA, and the synthesis of $p$-TSMo. Although the polymerization reactivity was thought to be reduced by the $\left[-\mathrm{P}(\mathrm{C}=\mathrm{O})(\mathrm{OH})_{2}\right]$ moiety, a new initiator system CEBA-p-TSMo- $t$-BPMA ${ }^{23)}$ enabled increasing cohesive force of adhesive resin between the adherends ${ }^{15}$.

Table 1 Compositions of the experimental composite-type adhesive resins examined in this study.

\begin{tabular}{lrlr}
\hline \multicolumn{2}{c}{ Powder $(\mathrm{Wt} \%)^{\dagger}$} & \multicolumn{2}{c}{ Liquid $(\mathrm{wt} \%)^{\dagger}$} \\
\hline Si-treated filler & 96.50 & IPDI-HEMA & 57.25 \\
CEBA & 1.00 & Gr-GMA & 20.00 \\
Acidic monomer & 1.50 & TEGDMA & 20.00 \\
(6-MHPA, 6-AHPA, 10-MDPA, & & -TSMo & 2.00 \\
VBPA, 4-AETA, 4-META) & & DEPT & 0.75 \\
$t$-BPMA & 1.00 & BHT & $500 \mathrm{ppm}$ \\
\hline
\end{tabular}

$\dagger$ Powder/Liquid ratio:3.5/1

Abbreviations:CEBA: 1-cyclohexyl-5-ethylbarbituric acid, t-BPMA: tert-butylperoxymaleic acid, 6 MHPA: 6-methacryloxyhexyl phosphonoacetate, 6-AHPA: 6-acryloxyhexyl phosphonoacetate, 10MDPA: 10-methacryloxydecyl phosphonoacetate, VBPA: vinylbenzyl phosphonic acid , 4-AET: 4acryloxyethyltrimellitic acid, 4-AETA: 4-acryloxyethyltrimellitic anhydride, 4-META: 4methacryloxyethyltrimellitic anhidride, IPDI-HEMA: dimethacryloxyethyl isophorone diurethane, Cr-GMA: $p$-(2-hydroxy-3-methacryloxypropyl)-cresol, TEGDMA: triethyleneglycol dimethacrylate, DEPT: $N, N$-(dihydroxyethyl)-p-toluidine, $p$-TSMo $p$-toluene sulifinate morphoride, BHT:butylated hydroxytoluene.

Preparation of other reagents

Si-treated fillers [a mixture of $75 \%$ Si-treated silica (mean particle size: $1.5 \mu \mathrm{m}$ ) and $25 \%$ Si-treated $\left.\mathrm{BaSO}_{4}\right]^{23)}$ were prepared by treating the filler mixture with $\mathrm{Y}$-methacryloxypropyl trimethoxysilane (KBM503, Shinetsu Chemical Co. Ltd., Niigata, Japan). As for $p$-(2-hydroxy 3-methacryloxypropyl)-cresol (CrGMA) (white crystals, $\mathrm{mp} 37^{\circ} \mathrm{C}$ ), it was synthesized by the addition of p-cresol (Cr) and glycidyl methacrylate (GMA) in a 1:1 molar ratio ${ }^{23)}$. Dimethacryloxyethyl isophorone diurethane [IPDIHEMA: an adduct of isophorone diisocyanate (IPDI) and 2-hydroxyethyl methacrylate (HEMA) in a 1:2 molar ratio, translucent viscous liquid containing 20 wt\% ethyleneglycol dimethacrylate (EGDMA) $]^{23)}$, VBPA6), 4-AETA (white crystals, $\left.\mathrm{mp} 43.0-45.0^{\circ} \mathrm{C}\right)^{19}$, and 4-META (white needle crystals, mp 95.0-96.0 $\left.{ }^{\circ} \mathrm{C}\right)^{1)}$ were synthesized, according to the respective methods previously reported. Butylated hydroxytoluene (BHT) was purchased from Wako Pure Chemical Industries Ltd. (Osaka, Japan) and used without further purification.

Preparation of experimental adhesive resins

Seven experimental chemically cured composite-type adhesive resins consisting of powders and liquids were prepared from fillers: Si-treated silica and $\mathrm{BaSO}_{4}$; matrix resins: IPDI-HEMA, TEGDMA, CrGMA; adhesive monomers: 6-MHPA, 6-AHPA, 10MDPA, 4-AETA, 4-META, VBPA, and None (control); polymerization initiators: CEBA, p-TSMo, $t$-BPMA; and polymerization inhibitor: BHT. Table 1 lists the compositions.

Tensile bond strength measurement

1) Preparation of adherends 
Table 2 Identification characteristics of the synthesized methacryloxyalkyl or acryloxyalkyl phosphonoacetates in this study.

\begin{tabular}{|c|c|c|c|c|c|}
\hline Monomer & Appearance & $\begin{array}{l}\text { Yield } \\
(\%)\end{array}$ & $\begin{array}{c}{ }^{\mathrm{I}} \mathrm{H} \text { NMR spectra } \\
(\delta, \mathrm{ppm})\end{array}$ & $\begin{array}{l}\text { IR spectra } \\
\left(\text { neat, } \mathrm{cm}^{-1}\right)\end{array}$ & $\begin{array}{c}\text { Elemantal } \\
\text { Analysis }\end{array}$ \\
\hline 6-MHPA & $\begin{array}{l}\text { Light yellow } \\
\text { viscous } \\
\text { liquid }\end{array}$ & 51.9 & $\begin{array}{l}1.3-1.8\left[8 \mathrm{H},-\mathrm{CH}_{2}-\left(\mathrm{CH}_{2}\right)_{4}^{-}\right. \\
\left.\mathrm{CH}_{2^{-}}\right], 1.9\left(3 \mathrm{H}_{3}-\mathrm{CH}_{3}\right), \\
2.6-2.9\left(2 \mathrm{H},-\mathrm{OOC}-\mathrm{CH}_{2^{-}}\right. \\
\mathrm{P}), 4.0,4.1(4 \mathrm{H},-\mathrm{COO}- \\
\left.\mathrm{CH}_{2}-\times 2\right), 5.6,6.0(2 \mathrm{H}, \\
\left.\underline{\mathrm{CH}_{2}}=\mathrm{C}<\right), 9.5[2 \mathrm{H},- \\
\left.\mathrm{P}(=\mathrm{O})(\mathrm{OH})_{2}\right]\end{array}$ & $\begin{array}{l}1296(\mathrm{vP}=\mathrm{O}) \\
1008,939(\mathrm{vP}- \\
\frac{\mathrm{OH}}{(\mathrm{vC}}=1636 \\
(\mathrm{C})\end{array}$ & $\begin{array}{l}\text { Theoretical } \\
\text { calculations for } \\
\mathrm{C}_{12} \mathrm{H}_{22} \mathrm{O}_{7} \mathrm{P} \text { : } \\
\mathrm{C}, 46.75 \% \text {; } \mathrm{H}, 6.82 \% \\
\text { Experimental: } \\
\mathrm{C}, 46.84 \% \\
\mathrm{H}, 6.78 \%\end{array}$ \\
\hline 6-AHPA & $\begin{array}{l}\text { Light yellow } \\
\text { viscous } \\
\text { liquid }\end{array}$ & 42.8 & $\begin{array}{l}1.3-1.8\left[8 \mathrm{H},-\mathrm{CH}_{2}-\left(\mathrm{CH}_{2}\right)_{4}^{-}\right. \\
\left.\mathrm{CH}_{2}\right], 2.1,2.7(2 \mathrm{H},- \\
\left.\mathrm{OOC}-\mathrm{CH}_{2}-\mathrm{P}\right), 4.0,4.1 \\
\left(4 \mathrm{H},-\mathrm{COO}-\mathrm{CH}_{2}-\times 2\right), \\
5.8,6.2\left(3 \mathrm{H}, \mathrm{CH}_{2}=\mathrm{CH}-\right), \\
9.5\left[2 \mathrm{H},-\mathrm{P}(=\mathrm{O})(\mathrm{OH})_{2}\right]\end{array}$ & $\begin{array}{l}\text { 1296(vP = O), } \\
1010,940(\mathrm{vP}- \\
\underline{\mathrm{OH}}), \quad 1636(\mathrm{vC}=\mathrm{C})\end{array}$ & $\begin{array}{l}\text { Calculations for } \\
\mathrm{C}_{11} \mathrm{H}_{17} \mathrm{O}_{7} \mathrm{P} \text { : } \\
\text { C, } 45.21 \% \text {; H, } 5.82 \% \\
\text { Experimental: } \\
\text { C, } 44.92 \% \\
\mathrm{H}, 5.73 \%\end{array}$ \\
\hline 10-MDPA & $\begin{array}{l}\text { Ligth yellow } \\
\text { viscous } \\
\text { liquid }\end{array}$ & 44.0 & $\begin{array}{l}1.2-1.8\left[16 \mathrm{H},-\mathrm{CH}_{2^{-}}\right. \\
\left.\left(\mathrm{CH}_{2}\right)_{8}-\mathrm{CH}_{2}-\right], 1.9(3 \mathrm{H},- \\
\mathrm{CH}_{3}, 2.6-3.0(2 \mathrm{H},-\mathrm{OOC}- \\
\left.\mathrm{CH}_{2}-\mathrm{P}\right), 4.0,4.1(4 \mathrm{H},- \\
\left.\mathrm{COO}-\mathrm{CH}_{2}-\times \quad 2\right), 5.6,6.0 \\
(2 \mathrm{H}, \mathrm{CH} 2=\mathrm{C}<), 9.5[2 \mathrm{H},- \\
\left.\mathrm{P}(=\mathrm{O})(\mathrm{OH})_{2}\right]\end{array}$ & $\begin{array}{l}\text { 1297(vP = O), } \\
1011,942(\mathrm{vP}- \\
\left.\frac{\mathrm{OH}}{(\mathrm{vC}}\right), 1637 \\
\end{array}$ & $\begin{array}{l}\text { Calculations for } \\
\mathrm{C}_{16} \mathrm{H}_{29} \mathrm{O}_{7} \mathrm{P} \text { : } \\
\mathrm{C}, 52.75 \% \\
\mathrm{H}, 7.97 \% \\
\text { Experimental: } \\
\mathrm{C}, 52.05 \% \\
\mathrm{H}, 7.83 \%\end{array}$ \\
\hline
\end{tabular}

Abbreviations: 6-MHPA: 6-methacryloxyhexyl phosphonoacetate, 6-AHPA: 6-acryloxyhexyl phosphonoacetate, 10-MPPA: 10-methacryloxydecylphosphonoacetate.

Freshly extracted bovine incisors were used as substitutes for human specimens ${ }^{26)}$, due to the large number of teeth required in this study. Bovine teeth with the root cut off were embedded in epoxy resin, ground to enamel or dentin using 600-grit $\mathrm{SiC}$ abrasive paper under running water, and then air-dried (ground enamel or dentin). A dental $\mathrm{Ni}-\mathrm{Cr}$ alloy (Shofu Summalloy Nickel, Shofu Inc., Kyoto, Japan) was cast with a casting machine (Shofu Argon Caster, Shofu Inc., Kyoto, Japan), and a metal rod (4.5 $\pm 0.1 \mathrm{~mm}$ in diameter, $6.0 \pm 0.1 \mathrm{~mm}$ in height) and a metal plate $(3.0 \times 8.0 \times 10.0, \mathrm{~mm})$ were also prepared. Adhesive surfaces of the rod and plate were flatground using 600-grit $\mathrm{SiC}$ abrasive paper, sandblasted with aluminum oxide, and cleaned ultrasonically for five minutes (sandblasted $\mathrm{Ni}-\mathrm{Cr}$ alloy). A dental porcelain (Shofu Unibond Vintage, Shofu Inc., Kyoto, Japan) plate $(3.0 \times 8.0 \times 10.0, \mathrm{~mm})$ was prepared by firing, then ground with 600-grit $\mathrm{SiC}$ abrasive paper (ground porcelain).

2) Tensile bond testing

Mixed adhesive resins $(\mathrm{P} / \mathrm{L}=3.5)$ listed in Table 1 were cured for 6.0-7.0 minutes at $23 \pm 1^{\circ} \mathrm{C}$. Each mixed adhesive resin was placed on an adherend, and made to bond between the sandblasted $\mathrm{Ni}-\mathrm{Cr}$ alloy rod and ground enamel or ground dentin or ground porcelain or sandblasted plate. After 30 minutes, the test specimens $(n=10)$ were immersed in distilled water at $37^{\circ} \mathrm{C}$ for 24 hours. Tensile bond strength was then measured using a mechanical testing machine (Instron 5567, Instron Co., USA) at a crosshead speed of $1 \mathrm{~mm} / \mathrm{min}$.

All tests were conducted at $23 \pm 1^{\circ} \mathrm{C}$. Fractured surfaces of specimens were examined in a microscope, whereby adhesive, cohesive, or mixed failures were recorded. The mean and standard deviation for the load at failure was calculated, and the results were subjected to one-way analysis of variance (ANOVA) followed by Newman-Keuls multiple comparison test.

\section{RESULTS}

Synthesis of new phosphonic acid monomers

Phosphonic acid monomers were synthesized as pale yellow viscous liquids with yields of $42.8-51.9 \%$. They were spectrally identified as new compounds by ${ }^{1} \mathrm{H}$ NMR and IR spectra in typical assignments of ${ }^{1} \mathrm{H}$ NMR band of $7.6 \delta\left[2 \mathrm{H},-\mathrm{P}(=\mathrm{O})(\mathrm{OH})_{2}\right]$ and IR band of 1292-1296 $\mathrm{cm}^{-1} \quad(\mathrm{vP}=\mathrm{O})$. Synthesized monomers were confirmed to be novel 6-methacryloxyhexyl phosphonoacetate (6-MHPA) $\left(3, \mathrm{R}=\mathrm{CH}_{3}, \mathrm{n}=6, \mathrm{~m}=1\right.$, Fig. 1), 6-acryloxyhexyl phosphonoacetate (6-AHPA) (3, $\mathrm{R}=\mathrm{H}, \mathrm{n}=6, \mathrm{~m}=1$, Fig. 1), and 10-methacryloxydexyl phosphonoacetate (10-MDPA) (3, $\mathrm{R}=\mathrm{CH}_{3}, \mathrm{n}=10, \mathrm{~m}=1$, Fig. 1). The identification characteristics of the synthesized phosphonic acid monomers in this study are summarized in Table 2. Although the yields of these experimental phosphonic monomers were not so high, the elemental analysis data and ${ }^{1} \mathrm{H}$ NMR spectra for these experimental monomers revealed that they were 
Table 3 Effect of several adhesive monomers on tensile bond strengths of experimental composite-type adhesive resins between sandblasted $\mathrm{Ni}-\mathrm{Cr}$ alloy rod and unetched ground enamel or unetched ground dentin.

\begin{tabular}{|c|c|c|c|c|}
\hline \multirow{2}{*}{$\begin{array}{l}\text { Adhesive } \\
\text { monomers }\end{array}$} & \multicolumn{4}{|c|}{ Bond strength $(\mathrm{MPa})$ of $\mathrm{Ni}-\mathrm{Cr}$ alloy to } \\
\hline & $\begin{array}{l}\text { Unetched enamel* } \\
\qquad(n=10)^{\dagger}\end{array}$ & $\mathrm{A} / \mathrm{M} / \mathrm{C}(\%)^{\S}$ & $\begin{array}{l}\text { Unetched dentin* } \\
\qquad(n=10)^{\dagger}\end{array}$ & $\mathrm{A} / \mathrm{M} / \mathrm{C}(\%)^{\S}$ \\
\hline 6-MHPA & $12.8 \pm 3.3^{\mathrm{a}}$ & $90 / 10 / 0$ & $5.5 \pm 1.3^{\mathrm{a}}$ & $100 / 0 / 0$ \\
\hline 6-AHPA & $12.5 \pm 2.8^{\mathrm{a}}$ & $90 / 10 / 0$ & $5.3 \pm 1.1^{\mathrm{a}}$ & $100 / 0 / 0$ \\
\hline 10-MDPA & $13.2 \pm 3.8^{\mathrm{a}}$ & $80 / 20 / 0$ & $5.8 \pm 1.2^{\mathrm{a}}$ & $100 / 0 / 0$ \\
\hline VBPA & $5.8 \pm 2.2^{\mathrm{b}}$ & $100 / 0 / 0$ & $2.5 \pm 0.8^{b}$ & $100 / 0 / 0$ \\
\hline 4-AETA & $9.4 \pm 3.6^{\mathrm{a}}$ & $90 / 10 / 0$ & $5.1 \pm 1.6^{\mathrm{a}}$ & $100 / 0 / 0$ \\
\hline 4-META & $9.8 \pm 3.2^{\mathrm{a}}$ & $90 / 10 / 0$ & $5.2 \pm 1.3^{\mathrm{a}}$ & $100 / 0 / 0$ \\
\hline None & $1.6 \pm 0.7^{\mathrm{c}}$ & $100 / 0 / 0$ & $0.4 \pm 0.2^{c}$ & $100 / 0 / 0$ \\
\hline
\end{tabular}

*Unetched enamel and dentin: bovine enamel and dentin ground with 600-grit $\mathrm{SiC}$ abrasive paper and bonded without acid etching.

$\dagger$ Values are means (standard deviation). Groups from the same column that are identified with the same superscript letters are not significantly different $(\mathrm{p}<0.01)$.

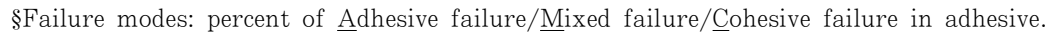

Table 4 Effect of several adhesive monomers on tensile bond strengths of experimental composite-type adhesive resins between sandblasted $\mathrm{Ni}-\mathrm{Cr}$ alloy rod and dental porcelain plate or sandblasted Ni-Cr alloy plate.

\begin{tabular}{|c|c|c|c|c|}
\hline \multirow{2}{*}{$\begin{array}{l}\text { Adhesive } \\
\text { monomers }\end{array}$} & \multicolumn{4}{|c|}{ Bond strength (MPa) of Ni-Cr alloy to } \\
\hline & $\begin{array}{l}\text { Porcelain* } \\
(\mathrm{n}=10)^{\dagger}\end{array}$ & $\mathrm{A} / \mathrm{M} / \mathrm{C}(\%)^{\S}$ & $\begin{array}{c}\mathrm{Ni}-\mathrm{Cr} \text { alloy* } \\
(\mathrm{n}=10)^{\dagger}\end{array}$ & $\mathrm{A} / \mathrm{M} / \mathrm{C}(\%)^{\S}$ \\
\hline 6-MHPA & $15.0 \pm 4.4^{\mathrm{a}}$ & $0 / 30 / 70$ & $47.3 \pm 8.5^{\mathrm{a}}$ & $0 / 10 / 90$ \\
\hline 6-AHPA & $14.1 \pm 3.5^{\mathrm{a}}$ & $0 / 30 / 70$ & $46.2 \pm 7.2^{\mathrm{a}}$ & $0 / 10 / 90$ \\
\hline 10-MDPA & $15.7 \pm 3.8^{\mathrm{a}}$ & $0 / 20 / 80$ & $48.8 \pm 10.5^{\mathrm{a}}$ & 0/0/100 \\
\hline VBPA & $8.0 \pm 3.8^{\mathrm{b}}$ & $20 / 50 / 10$ & $30.8 \pm 5.8^{\mathrm{b}}$ & $0 / 40 / 60$ \\
\hline 4-AETA & $13.2 \pm 4.8^{\mathrm{a}}$ & $0 / 30 / 70$ & $47.5 \pm 8.0^{\mathrm{a}}$ & 0/0/100 \\
\hline 4-META & $13.8 \pm 3.5^{\mathrm{a}}$ & $0 / 30 / 70$ & $46.5 \pm 7.6^{\mathrm{a}}$ & $0 / 0 / 100$ \\
\hline None & $4.0 \pm 0.5^{c}$ & $100 / 0 / 0$ & $17.2 \pm 2.5^{c}$ & $70 / 30 / 0$ \\
\hline
\end{tabular}

*Porcelain: Shofu Unibond Vintage (Shofu Inc.,Japan) plate was ground with 600-grit SiC adrasive paper $.^{*} \mathrm{Ni}-\mathrm{Cr}$ alloy: Shofu Summalloy Ni (Shofu Inc., Japan) plate cast was sandblasted with aluminum oxide.

$\dagger$ Values are means (standard deviation); groups from the same column that are identified with the same superscript letters are not significantly different $(\mathrm{p}<0.01)$.

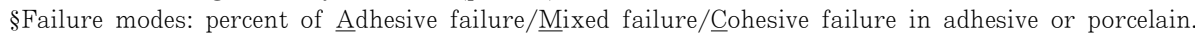

synthesized with high purity.

\section{Tensile bond strength measurement}

Table 3 presents the tensile bond strengths of the seven experimental adhesive resins - comprising 6MHPA, 6-AHPA, 10-MDPA, 4-AETA, 4-META, VBPA, or None (a control) together with CEBA/pTSMo/t-BPMA initiator ${ }^{23)}$ - between sandblasted Ni$\mathrm{Cr}$ alloy rod and unetched enamel or unetched dentin, while Table 4 presents the tensile bond strengths with ground porcelain or sandblasted $\mathrm{Ni}-\mathrm{Cr}$ alloy plate. It was apparent that the bond strengths to all adherends were significantly affected by the inclusion of acidic adhesive monomers when compared with the control formulation (i.e., no acidic adhesive monomers included). Statistical analysis (ANOVA) indicated that there were no significant differences among the adhesive monomers of 6-MHPA, 6-AHPA, 10-MDPA, 4-AETA, and 4-META in the bond strengths to unetched enamel (9.4-13.2 MPa), unetched dentin (5.1-
5.8 MPa), ground porcelain (13.2-15.7 MPa), and sandblasted Ni-Cr alloy (46.2-48.8 $\mathrm{MPa})$, whereas significant differences were found when compared with that of VBPA to the respective adherends $(p<0.01)$. Note that the unetched dentin and sand blasted $\mathrm{Ni}-\mathrm{Cr}$ alloy, these adhesive monomers without VBPA yielded similar tensile bond strength values. However, with unetched ground enamel and ground porcelain, the bond strengths manifested the following tendency: $10-\mathrm{MDPA}=6$-MHPA $=6$-AHPA $>4$ META $=4$-AETA, whereby 10-MDPA revealed the highest bond strength value to all the adherends tested.

With the unetched ground enamel substrate, significant differences were observed between the bond strengths attained with the new experimental phosphonic acid monomers (12.5-13.2 MPa) and VBPA $(5.8 \mathrm{MPa})(\mathrm{p}<0.01)$. With the unetched ground dentin substrate, significant differences were observed between the tensile bond strengths attained with the 
experimental phosphonic acid monomers (5.3-5.8 MPa) and VBPA $(2.5 \mathrm{MPa})(\mathrm{p}<0.01)$. With the ground porcelain, the experimental phosphonic acid monomers exhibited significantly higher tensile bond strengths $(14.1-15.7 \mathrm{MPa})$ than VBPA $(8.0 \mathrm{MPa})(\mathrm{p}<0.01)$. With the sandblasted $\mathrm{Ni}-\mathrm{Cr}$ alloy, the experimental phosphonic acid monomers also exhibited significantly higher tensile bond strengths (46.2-48.8 MPa) than VBPA $(30.8 \mathrm{MPa})(\mathrm{p}<0.01)$.

The tensile bond strengths of the experimental phosphonic acid monomers to the metal alloy were, in general, 3.5-4 times higher than their corresponding tensile bond strengths to enamel. The tensile bond strength values of all adhesive monomers to unetched ground enamel were higher than that to unetched ground dentin. Since the hydrophobic adhesive resins contained no water, low bond strengths to the ground dentin substrate were thus observed. As for comparison between methacryloyl ester and acryloyl ester, no significant differences in tensile bond strength to all adherends used were observed between 6-MHPA and 6-AHPA or 4-META and 4AETA $(\mathrm{p}<0.01)$.

Examination of the fractured surfaces after tensile bond testing revealed $80-100 \%$ adhesive failures for unetched enamel substrate and $100 \%$ adhesive failure for unetched ground dentin substrate. On the other hand, $70-80 \%$ and $90-100 \%$ cohesive failures occurred within the adhesive layer with the porcelain substrate and metal substrate respectively, when these experimental phosphonic acid monomers were included in the resin formulations (Tables 3 and 4).

\section{DISCUSSION}

In dental adhesive formulations, super-adhesive monomer is an extremely valuable component. As such, numerous adhesive monomers have been synthesized and evaluated for their adhesion-promoting functions ${ }^{1-22}$. In the same vein, previous works in our research series performed the syntheses of phosphonic and carboxylic acid types of adhesive monomers and the evaluation of their bonding performance ${ }^{14,15,19,21,23)}$. Figure 1 shows the general schema of the syntheses of seven kinds of phosphonic acid monomers $\left[\mathrm{R}-\mathrm{P}(=\mathrm{O})(\mathrm{OH})_{2}\right]$ (3) and six kinds of methacryloxyalkyl or acryloxyalkyl trimellitic acid (5) and their anhydrides (4). In the present study, three kinds of new phosphonic acid monomers (6MHPA, 6-AHPA, 10-MDPA) (3, $\mathrm{m}=1$, Fig. 1) were synthesized, and their multi-purpose bonding performance together with CEBA-p-TSMo-t-BPMA initiator $^{23)}$ were investigated. As this study investigated to assess the efficacy of the structure of acidic monomers on bonding performance, a chemicalapproach investigation on the molecular design of adhesive monomers would thus seem a logical research strategy to reap important information for dental adhesive formulations.

In the molecular design of adhesive monomers, acidic hydrophilic moieties are particularly important because they are highly correlated with the chemical interaction of adhesive monomers with adherends ${ }^{27-29}$. Similar to the chemical interaction of acidic carboxyl group with hydroxyapatite ${ }^{27-29)}$, it was hypothesized that phosphonic acid monomers as a ligand monomer achieved good chemical interaction with both hydroxyapatite in tooth and metal oxide on the metal surface ${ }^{15)}$. In this study, the phosphonic acid moiety $\quad\left[\mathrm{C}-\mathrm{P}(=\mathrm{O})(\mathrm{OH})_{2}\right]$ was produced from phosphonoacetic acid (PPA) [HOOC- $\left.\mathrm{CH}_{2}-\mathrm{P}(=\mathrm{O})(\mathrm{OH})_{2}\right]$ (1, $\mathrm{m}=1$, Fig. 1A), which was synthesized from ethyl diethylphosphonoacetate $\left[\right.$ EtOOC- $\left.\mathrm{CH}_{2}-\mathrm{P}(=\mathrm{O})(\mathrm{OEt})_{2}\right][1$ ', $\mathrm{m}=1$, Fig. 1A (b)] by hydrolysis. For the formation of carbon-phosphorus bonds $[>\mathrm{P}(=\mathrm{O})-\mathrm{C}]$, alkyl dialkylphosphonate $\left[\mathrm{R}_{1} \mathrm{OOC}-\mathrm{R}_{1}-\mathrm{P}(=\mathrm{O})\left(O \mathrm{R}_{1}\right)_{2}\right]$ is a valuable synthetic intermediate that can be synthesized by either the ring-opening reaction of alkyl lactone compounds with trialkylphosphite [Fig. 1A (a)] or by Michaelis-Arbuzov rearrangement ${ }^{30)}$ [Fig. 1A (b)]. The latter is the reaction of trialkylphosphite with alkyl-alkylcarboxylate halides and is still frequently used in organophosphorus chemistry ${ }^{311}$. During the transformation, a tervalent phosphorus [P(III)] is converted into a pentavalent phosphorus $[\mathrm{P}(\mathrm{V})]$, which involves the conversion of $>\mathrm{P}-\mathrm{O}-\mathrm{C}$ linkage into $>\mathrm{P}(=\mathrm{O})-\mathrm{C}$ linkage $\mathrm{e}^{30}$.

Hydrophobic alkyl and polymerizable moieties can be produced from monohydroxyalkyl methacrylates or monohydroxyalkyl acrylates $(\mathrm{OH}$ monomer 2, Fig. 1C). For carbon chain extension, the $\mathrm{OH}$ monomer 2 is still frequently used as a valuable synthetic intermediate in the design of adhesive monomers. The $\mathrm{OH}$ monomer 2 previously reacted with either phosphoric acid or anhydrous trimellitic chloride to yield the corresponding phosphate monomers of Phenyl-(-2,3) and $\mathrm{MDP}^{4)}$ or carboxylic acid-type monomers of 4-AETA ${ }^{14,19,21,23)}$, 4-AET ${ }^{14,19,23)}$, 4-META ${ }^{1,14)}$, 4-methacryloyloxy-iso-propyltrimellitic anhydride (4MPTA) $)^{14}$, 4-methacryloyloxyhexyl trimellitic anhydride (4-MHTA $)^{14)}$, and 4-methacryloyloxydecyl trimellitic anhydride (4-MDTA $)^{14)}(4$ and 5, Fig. 1C). Recently, the $\mathrm{OH}$ monomer 2 also reacted with carboxyethyl phosphonic acid [HOOC- $\mathrm{CH}_{2} \mathrm{CH}_{2}-\mathrm{P}(=\mathrm{O})$ $\left.(\mathrm{OH})_{2}\right](1, \mathrm{~m}=2$, Fig. 1A) to form phosphonic acid monomers (3, Fig. 1C) of 5-methacryloxypentyl 3phosphonopropionate (5-MPPP), 6-methacryloxyhexyl 3-phosphonopropionate (6-MHPP), 6-acryloxyhexyl 3phosphonopropionate (6-AHPP), and 10-methacryloxydecyl 3-phosphonopropionate (10-MDPP) with a light yellow viscous liquid ${ }^{15}$. In this study, the $\mathrm{OH}$ monomer 2 further reacted with PPA [HOOC- $\mathrm{CH}_{2}$ $\left.\mathrm{P}(=\mathrm{O})(\mathrm{OH})_{2}\right](\mathbf{1}, \mathrm{m}=1$, Fig. 1A) to yield new phosphonic acid monomers (3, Fig. 1C) of 6-methacryloxyhexyl 
phosphonoacetate (6-MHPA: $3, \quad \mathrm{~m}=1, \quad \mathrm{n}=6), \quad 6$ acryloxyhexyl phosphonoacetate (6-AHPA: 3, $\mathrm{m}=1$, $\mathrm{n}=6$ ), and 10-methacryloxydecyl phosphonoacetate (10MDPA: $3, m=1, n=10)$. The viscous appearance of the three synthesized phosphonic acid monomers was caused by the presence of long alkyl chains in the structure of the phosphonic acid monomers.

Due to their self-etching capability, it was anticipated that the synthesized phosphonic acid monomercontaining adhesive resins would have potential in prosthodontic and orthodontic applications. Accordingly then, the multi-purpose bonding performance of the phosphonic acid monomers against a conventional VBPA, together with CEBA-p-TSMo- $t$ BPMA initiator ${ }^{23)}$, was investigated. Similar to conventional phosphate monomers $\left[\mathrm{R}-\mathrm{O}-\mathrm{P}(=\mathrm{O})(\mathrm{OH})_{2}\right]$, it was anticipated that experimental phosphonic acid monomers $\left[\mathrm{R}-\mathrm{P}(=\mathrm{O})(\mathrm{OH})_{2}\right]$ should possess adhesionpromoting function. To clarify this issue, self-curing adhesive resins were formulated using a simple methodology of powders and liquids, whereby the concentration of adhesive monomers was defined as $1.5 \mathrm{wt}$ $\%^{23)}$ in powder. It was found that the experimental phosphonic acid monomers-6-MHPA, 6-AHPA, and 10-MDPA - exhibited significant effectiveness on adhesion to unetched ground enamel, ground porcelain, and sandblasted $\mathrm{Ni}-\mathrm{Cr}$ alloy. Indeed, their bond strengths were significantly higher than that of conventional VBPA.

Although VBPA and VPA have the phosphonic acid moiety, adhesives containing these monomers formulated with ethyl alcohol exhibited negligible adhesion to hard dental tissues ${ }^{6}$. We speculated that low bond strength was caused not only by the minimized ionization of VBPA or VPA in ethyl alcohol, but also that their molecular structures had no flexible alkyl spacer ${ }^{15)}$. Regarding methylene chain [-(CH2) $\left.)^{-}\right]$ as a spacer group in the structure of adhesive monomers, Omura and Yamauchi ${ }^{4)}$ reported that bond strength to dentin or $\mathrm{Ni}-\mathrm{Cr}$ alloy of methacryloxyalkyl dihydrogen phosphate was affected by the methylene chain. It was found that 10MDP (=C10: 10 carbon atoms in methylene chain) or 6-methacryloxyhexyl dihydrogen phosphate (6-MHP) (=C6) yield higher bond strength than 2methacryloxyethyl dihydrogen phosphate (2-MEP) $(=\mathrm{C} 2)$, thereby concluding that flexible methylene chain in phosphate monomers was necessary for adhesion to both dentin and metal ${ }^{4}$.

Our recent work ${ }^{15}$ showed that the bond strengths of methacryloxyalkyl or acryloxyalkyl 3phosphonopropionates with BPO-DEPT-BPBA-type initiator ${ }^{23}$ to unetched ground enamel or $\mathrm{Ni}-\mathrm{Cr}$ alloy after 2,000 thermal cycles were significantly higher than that of conventional VBPA $(p<0.01)$. On this note, it was concluded that the enhanced bonding efficacy of new phosphonic acid monomers was attributed to their flexible methylene chain, i.e., C6 or C10, as well as their phosphonic acid moiety ${ }^{15}$. Accordingly then, methacryloxyalkyl or acryloxyalkyl phosphonoacetates with flexible C6 or C10 methylene chains were synthesized in this study. As per our expectations, the bonding performance of 10-MDPA that comprised the more flexible $\mathrm{C} 10$ moiety was similar to that of $10-\mathrm{MDP}^{4)}$. Conversely, for conventional VBPA, its statistically lower bond strengths as compared with the new phosphoric acid monomers was caused by the absence of flexible alkyl spacera finding similar to that of our recent work $^{15}$. It was once again suggested that the flexible methylene chain contributed to forming a stable molecular layer on the surface of several adherends, with which the phosphonic acid moiety interacted. Furthermore, apart from the effect of flexible alkyl spacer on adhesion, it was thought that the significant differences between VBPA and new phosphonic acid monomers on adhesion might be caused by differences in copolymerization reactivity of either a styrene-type monomer $\left(\mathrm{CH}_{2}=\mathrm{CH}-\mathrm{Ph}-\mathrm{R}\right.$; VBPA $)$ or an acrylate-type monomer $\left(\mathrm{CH}_{2}=\mathrm{CR}_{1}-\mathrm{COO}-\mathrm{R}_{2} ; 6\right.$-MHPA, 6-AHPA, 10-MDPA) with the other methacrylate monomers, such as urethane dimethacrylate, incorporated in the adhesive resins. Therefore, based on the findings, we rejected the null hypothesis that there were no significant differences between the new (6MHPA, 6-AHPA, 10-MDPA) and conventional (VBPA) phosphonic acid monomers on adhesion to the four kinds of adherend.

Although this study revealed that the bonding efficacy of phosphonic acid-type adhesive monomers was correlated with the flexible methylene chain, it was not thus indicated for the trimellitic anhydridetype adhesive monomers. While the trimellitic anhydride-type 4-AETA (C2) and 4-META (C2) (4, Fig. 1C) had no flexible methylene chain in their structures, their bond strengths to the four adherends used were not significantly different from that of phosphonic acid-type 6-MHPA (C6), 6-AHPA (C6), and 10-MDPA (C10) (3, Fig. $1 \mathrm{C}, \mathrm{m}=1)(\mathrm{p}<0.01)$. In particular, the bond strengths of the trimellitic anhydride-type monomers to unetched dentin and sandblasted $\mathrm{Ni}-\mathrm{Cr}$ alloy were similar to that of new phosphonic acid monomers on the corresponding adherends. It was thought that the interaction activity of trimellitic anhydride moiety with unetched dentin or sandblasted $\mathrm{Ni}-\mathrm{Cr}$ alloy was higher than that of phosphonic acid moiety. However, with unetched enamel and ground porcelain, the bond strength values of new phosphonic acid monomers exceeded that of trimellitic anhydride-type monomers. In particular, a higher bond strength to unetched ground enamel of phosphonic acid monomers could be attributed to the effective acidity of phosphonic acid moiety. 
With regard to the principle of adhesion, it is well known that an adhesive should possess the functions of both good chemical interaction with adherends (wettability) and good polymerization reactivity (hardening). Radical copolymerization reactivity of acrylic ester derivatives $\left(\mathrm{CH}_{2}=\mathrm{CH}-\mathrm{COO}-\mathrm{R}\right)$ with radical polymerizable monomers is generally higher than that of methacrylic ester derivatives $\left[\mathrm{CH}_{2}\right.$ $\left.=\mathrm{C}\left(\mathrm{CH}_{3}\right)-\mathrm{COO}-\mathrm{R}\right]^{32}$. On this note, it was thought that bonding performance could be influenced by copolymerization reactivity. To evaluate this issue, the acrylic esters of 6-AHPA and 4-AETA and methacrylic esters of 6-MHPA and 4-META were used in this study. However, there were no significant differences between 6-AHPA and 6-MHPA or 4AETA and 4-META in the corresponding bond strengths $(\mathrm{p}<0.01)$.

Although acidic groups have a good chemical interaction with tooth substrates and other adherends, it was anticipated that the acidic $\left[-\mathrm{P}(=\mathrm{O})(\mathrm{OH})_{2}\right]$ moiety would lead to low polymerization reactivity. A polymerization initiator system CEBA- $p$-TSMo- $t$ BPMA $^{23)}$ was employed in this study so that phosphonic acid monomers could perform their essential adhesion-promoting functions. This ternary initiator system markedly reduced the adverse effects on both polymerization and adhesion ${ }^{23}$, without undesirable salt formation ${ }^{16,23)}$ between the $\left[-\mathrm{P}(\mathrm{C}=\mathrm{O})(\mathrm{OH})_{2}\right]$ moiety and amines, and hence increased the cohesive force of adhesive resin between the adherends ${ }^{15}$.

Much attention has been paid to the use of barbituric acid derivatives for dental resins, derived from their $\mathrm{C}-\mathrm{H}$ active and amine-free polymerization initiating ability, since a study by Bredereck et al. ${ }^{25)}$. However, little attention has been paid to evaluate the effect of 5-monosubstituted barbituric acid (5MSBA) in combination with an aromatic sulfinate amides (ASA) and $t$-BPMA on adhesion ${ }^{23}$. To date, details of the polymerization initiation mechanism of these ternary initiator systems are still unknown. Nonetheless, the initiating behavior of 5-MSBA could be triggered by autooxidation of $\mathrm{C}-\mathrm{H}$ at the 5position of barbituric ring in the presence of a base $^{23,25)}$. Thus, the barbituric acid derivatives that can exhibit polymerization initiating function are restricted by the $\mathrm{C}-\mathrm{H}$ active $5-\mathrm{MSBA}^{25)}$, such as $\mathrm{CEBA}^{23)}$ and $\mathrm{BPBA}^{23)}$. As for sulfinate amide, i.e., $p$-TSMo ${ }^{23)}$, it could be synthesized by the reaction between an amide compound and an aromatic sufinate chloride, which could be prepared from an aromatic sulfinate sodium salt such as $p$-TSNa. It should be highlighted that while $p$-TSNa is insoluble in hydrophobic resins, $p$-TSMo is soluble in the resins which is definitely preferable for hydrophobic adhesive resin formulations.

Currently, adhesive resins are widely used for prosthetic and orthodontic applications. Although it was noted that acid-etching prior to the application of luting cements was detrimental to dentin bonding effectiveness $^{33}$, low bond strength values to smear layer-covered dentin (5.5-5.8 MPa) (Table 3) were observed in this study. It was revealed that due to poor ionization of acidic moieties in hydrophobic adhesives, these monomers failed to perform the essential bonding function with dentin ${ }^{28}$. Against this background, recently developed self-etching primers are attractive in that they create micromechanical retention in the hard dental tissues without the use of a separate acid-etching $\operatorname{step}^{10-13,19,20,34-41)}$. This capability enables them to bond orthodontic brackets ${ }^{39,40}$ or stainless steel rods ${ }^{41}$ with adhesive resins to unetched enamel. Further, it was found that a self-etching primer comprising 10-MDP provided efficient bonding of composite-type resin cement to titanium $(\mathrm{Ti})^{42}$, while an adhesive primer containing 6-MHPA was found to exhibit strong adhesion to zirconia- and alumina-based all-ceramic prostheses ${ }^{43}$. On this note, hydrolytically stable adhesive monomers should be incorporated in single-bottle water-based self-etch primers or all-in-one adhesives ${ }^{7.13)}$.

In addition to phosphonic acid and flexible methylene chain moieties, it was suggested that a super-adhesive monomer should possess hydrolytically stable moieties in the molecular structure. In general, a resin monomer bearing a strong acidic group has low radical copolymerization reactivity. Thus, to develop a multi-purpose adhesive resin and a waterbased single-bottle all-in-one adhesive, further investigations should be pursued with focus on the molecular design of super-adhesive monomer as well as seeking out an active polymerization initiator.

\section{CONCLUSION}

Three kinds of newly designed phosphonic acid monomers were synthesized with $42.8-51.9 \%$ yields. These new compounds were identified by ${ }^{1} \mathrm{H} \mathrm{NMR}$, IR, and elemental analysis to be methacryloxyalkyl or acryloxyalkyl phosphonoacetates: 6-MHPA, 6-AHPA, and 10-MDPA. After they were formulated into selfcured adhesive resin using a ternary initiator system CEBA-p-TSMo- $t$-BPMA, bonding study revealed that there were no significant differences among 6-MHPA, 6-AHPA, 10-MDPA, 4-AETA, and 4-META - except VBPA - on adhesion to unetched ground enamel, ground porcelain, and sandblasted $\mathrm{Ni}-\mathrm{Cr}$ alloy $(p<0.01)$. It was found that the new phosphonic acid monomers with the initiator system provided good multi-purpose bonding performance to enamel, dentin, porcelain, and metal. These findings revealed that the new phosphonic acid monomer-containing adhesive resins showed immense potential and promise in prosthodontic and orthodontic applications. 


\section{ACKNOWLEDGEMENTS}

The authors thank Dr. Hatsuo Ishida, Professor of the Department of Macromolecular Science and Engineering at Case Western Reserve University, Cleveland, Ohio, USA, for his most enlightening discussion during this study. This study was supported, in part, by grants R01 DE014911 and R01 DE15306 from the National Institute of Dental Research. The authors are grateful to Mrs. Michelle Barnes for her excellent secretarial support.

\section{REFERENCES}

1) Nakabayashi N. Bonding of restorative materials to dentin: the present status in Japan. Int Dent J 1985; 35(21):145-154.

2) Yamauchi J, Nakabayashi N, Masuhara E. Adhesive agents for hard tissue containing phosphoric acid monomers. ACS polymer preprints 1979; 20:594-595.

3) Yamauchi J, Masuhara E, Nakabayashi N, Shibutani K, Wada T. Method of filling a tooth cavity. United States Patent No. 4,259,075; 1981.

4) Omura I, Yamauchi J. Correlation between molecular structure of adhesive monomer and adhesive property. 1st Cong Int Dent Mater 1989; 356.

5) Klee JE. Self-adhesive polymerizable monomer and dental/medical compositions therefrom. European Patent Application 2004: EP1 462080 A1.

6) Anber M, Farley EP. Potential use of organic polyphosphonates as adhesives in the restoration of teeth. J Dent Res 1974; 53:879-888.

7) Moszner N, Zeuner F, Karl Fisher U, Rheinberger V. Monomers for adhesive polymers, $2^{\mathrm{a}}$. Synthesis and radical polymerization of hydrolytically stable acrylic phosphonic acids. Macromol Chem Phys 1999; 200:1062-1067.

8) Moszner N, Zeuner F, Angermann J, Fischer UK, Rheinberger V. Monomers for adhesive polymers, 4. Synthesis and radical polymerization of hydrolytically stable crosslinking monomers. Macromol Mater Eng 2003; 288:621-628.

9) Salz U, Zimmermann J, Zeuner F, Moszner N. Hydrolytic stability of self-etching adhesive systems. J Adhesive Dent 2005; 7(2):107-116.

10) Nishiyama N, Fujita K, Ikemi T, Maeda T, Suzuki K, Nemoto K. Efficacy of varying NMEP concentration in the NMGly-NMEP self-etching primer on the resin-tooth bonding. Biomaterials 2005; 26:2653-2661.

11) Nishiyama N, Suzuki K, Yoshida H, Teshima H, Nemoto K. Hydrolytic stability of methacrylamide in acidic aqueous solution. Biomaterials 2004; 25:965-969.

12) Moszner N, Salz U, Zimmermann J. Chemical aspects of self-etching enamel-dentin adhesives: a systematic review. Dent Mater 2005; 21:895-910.

13) Zimmermann J, Salz U, Moszner N. Hydrolytic stability of self-etching adhesive systems. J Adhes Dent
2005; 7:107-116.

14) Ikemura K, Endo T. Syntheses of adhesive-promoting monomers bearing carboxylic moieties and their bonding performance with new polymerization initiators comprising 5-monosubstituted barbituric acids. J Adhes Soc Jpn 1998; 34(4):138-149.

15) Ikemura K, Tay FR, Nishiyama N, Pashley DH, Endo T. Design of new phosphonic acid monomers for dental adhesives - synthesis of (meth)acryloxyalkyl 3phosphonopropionates and evaluation of their adhesion-promoting functions. Dent Mater J 2006; 25 (3): 566-575.

16) Bowen RL. Adhesive bonding of various materials to hard tooth tissues. II. Bonding to dentin promoted by a surface-active monomer. J Dent Res 1976; 44:895-902.

17) Bowen RL, Cobb EN, Rapson JE. Adhesive bonding of various materials to hard tooth tissues: Improvement in bond strength to dentin. J Dent Res 1982; 61 (9):1070-1076.

18) Bowen RL. Method for obtaining strong adhesive bonding of composite to dentin, enamel and other substances. United States Patent No. 4,521,550; 1985.

19) Ikemura K, Kouro $Y$, Endo $T$. Effect of 4acryloxyethyltrimellitic acid in a self-etching primer to ground dentin. Dent Mater J 1996; 15(2):132-143.

20) Hayakawa T, Nemoto K, Horie K. Adhesion of composite to polished dentin retaining its smear layer. Dent Mater 1995; 11:218-222.

21) Ikemura K, Kohro Y, Urabe S. Adhesive composition. Japanese Patent (B2) No.2865794; 1998.

22) Nishiyama N, Suzuki K, Takahashi K, Nemoto K. The pKa effects of the carboxylic acid in Nmethacryloyl-omega-amino acid on the demineralization and bond strengths to the teeth. Biomaterials 2004; 25:5441-5447.

23) Ikemura K, Endo T. Effect on adhesion of new polymerization initiator systems comprising 5monosubstituted barbituric acids, aromatic sulfinate amides and tert-butylperoxymaleic acid in dental adhesive. J Appl Polym Sci 1999; 72:1655-1668.

24) Tay FR, Pashley DH, Yiu CK, Sanares AM, Wei SH. Factors contributing to the incompatibility between simplified-step adhesives and chemically-cured or dualcured composites. Part I. Single-step self-etching adhesive. J Adhes Dent 2003; 5:27-40.

25) Bredereck VH, Fölisch B, Franz R. Über CH-aktive polymerization-initiation XIII. Mit polymerizationen und polymerization initiatoren. Makromol Chem 1966; 92:70 -90.

26) Schilke R, Bauss O, Lisson JA, Geurtsen W. Bovine dentin as a substitute for human dentin in shear bond strength measurements. Am J Dent 1999; 12:9296.

27) Yoshida Y, Van Meerbeek B, Nakayama Y, Snauwaert J, Hellemans L, Lambrechts P, Vanherle G, Wakasa K. Evidence of chemical bonding at biomaterial-hard 
tissue interfaces. J Dent Res 2000; 79:709-714.

28) Ikemura K, Tay FR, Hironaka T, Endo T, Pashley $\mathrm{DH}$. Bonding mechanism and ultrastructural interfacial analysis of a single-step, self-etching dentin bonding system. Dent Mater 2003; 19:707-715.

29) Ikemura K, Tay FR, Hironaka T, Negoro N, Pashley DH, Endo T. Study on dynamic interaction of a selfetching adhesive with dentin during contact time, using dynamic FT-IR/ATR and TEM measurements. J Dent 2006; (submitted).

30) Bhattacharya AK, Thyagarajan G. The MichaelisArbuzov rearrangement. Chem Rev 1981; 81:415-430.

31) Zhao CQ, Han LB, Tanaka M. Palladium-catalyzed hydrophosphorylation of allenes leading to regio- and stereoselective formation of allylphosphonates. Organometallics 2000; 19:4196-4198.

32) Ohtsu T. Chemistry of polymer synthesis, Kagaku Doujin Co., Tokyo, 1994; pp.71-1321.

33) Munck JD, Vargas M, Van Landuyt K, Hikita K, Lambrechts P, Van Meerbeek B. Bonding of an autoadhesive luting material to enamel and dentin. Dent Mater 2004; 20:963-971.

34) Chigira H, Koike T, Hasegawa T, Itoh K, Wakumoto $\mathrm{S}$, Hayakawa T. Effect of the self etching dentin primers on the bonding efficacy of a dentin adhesive. Dent Mater J 1989; 8:86-92.

35) Nishiyama N, Tay FR, Fujita K, Pashley DH, Ikemura K, Hiraishi N, King NM. Hydrolysis of functional monomers in a single-bottle self-etching primer-Correlation of ${ }^{13} \mathrm{C} \mathrm{NMR}$ and TEM findings. J Dent Res 2005; 85(5): 422-426.

36) Hayakawa $T$, kikutake $K$, Nemoto $K$. Influence of self-etching primer treatment on the adhesion of resin composite to polished dentin and enamel. Dent Mater 1998; 14:99-105.

37) Tay FR, Pashley DH. Aggressiveness of contemporary self-etching systems. I: Depth of penetration beyond dentin smear layers. Dent Mater 2001; 17:296308.

38) Pashley DH, Tay FR. Aggressiveness of contemporary self-etching adhesives. Part II: etching effects on unground enamel. Dent Mater 2001; 17:430-444.

39) Sirirungrojying S, Hayakawa T, Saito K, Meguro D, Nemoto K, Kasai K. Bonding durability between orthodontic brackets and human enamel treated with Megabond self-etching primer using 4-META/MMATBB resin cement. Dent Mater J 2004; 23(3):251-257.

40) Meguro D, Hayakawa T, Saito K, Kawasaki M, Kasai K. Effect of thermal cycling on shear bond strength with different types of self-etching primer for bonding orthodontic brackets using a MMA-based resin. Dent Mater J 2005; 24(1):30-35.

41) Hayakawa T, Fukushima T, Nemoto K. Tensile bond strength of 4-META/MMA-TBB resin to ground bovine enamel using self-etching primer. Dent Mater J 2004; 23(3):271-277.

42) Tsuchimoto Y, Yoshida Y, Mine A, Nakamura M, Nishiyama N, Van Meerbeek B, Suzuki K, Kuboki T. Effect of 4-MET- and 10-MDP-based primers on resin bonding to titanium. Dent Mater J 2006; 25(1):120124.

43) Sato T. The adhesive priming agent for zirconia- and alumina-based all-ceramics prosthesis. $2^{\text {nd }}$ Int Cong Adhes Dent 2005; 328 (\#S 09). 